\title{
ASPEK BIOLOGI DAN MANFAAT EKONOMI IKAN YANG TERTANGKAP DI SUNGAI SEBANGAU KOTA PALANGKA RAYA, KALIMANTAN TENGAH
}

\author{
(Biological Aspects And Economic Benefits Of Fish Captured In The Sebangau River \\ Palangka Raya City, Central Kalimantan)
}

\author{
Infa Minggawati ${ }^{1}$, Mardani $^{2}$, Ricke Marianty ${ }^{3}$ \\ ${ }^{1,2}$ Fakultas Perikanan, Universitas Kristen Palangka Raya \\ Email: ${ }^{1}$ infa41@gmail.com; ${ }^{2}$ mardanidani@42yahoo.com \\ ${ }^{3}$ Fakultas Peternakan, Universitas Kristen Palangka Rya \\ Jl. RTA. Milono Km. 8,5 Palangka Raya \\ Email: ${ }^{3}$ ricke.marianty@gmail.com
}

Article Submitted: 07-09-2020

Article Accepted : 23-09-2020

\begin{abstract}
This study aims to determine the biological aspects of snakehead fish, kerandang fish, fish, and kapar fish caught in the Sebagau river and the economic benefits for fishermen. Analysis of the relationship between length and weight of fish showed a close relationship between fish length and weight with a positive allometric growth pattern. The results of the analysis of fish stomach contents to determine fish food habits showed that the dominant food types were fish fry for Kehung fish 87\%, Kerandang 95\%, and Gabus 99\%. Meanwhile, for kapar fish, food dominates in the form of plants $72 \%$. The fishing ground along the Sebangau watershed is in a tributary that is directly connected to the Sebangau river. Economically, the fish catch in the Sebangau river by fishermen is sufficient to fulfill family life.
\end{abstract}

Keywords: Biological aspects, fish, economic benefits, Sebangau river

\section{PENDAHULUAN}

Ikan-ikan pada perairan gambut mempunyai kontribusi yang cukup penting untuk kesejahteraan masyarkat, terutama bagi para nelayan di perairan gambut (Minggawati et al 2020). Ikan-ikan pada perairan gambut sungai Sebangau, untuk beberapa jenis ikan seperti ikan gabus (Channa striata), ikan kapar(Belotia hasselti), ikan kehung (Channa lucius), ikan tapah (Wallago leeri) dan ikan kerandang(Channa pleurophthalma) dan ikan toman(Channa micropeltes), merupakan ikan yang banyak ditemukan di perairan sungai Sebangau dan mempunyai nilai ekonomis, sebagai ikan konsumsi dan diperdagangkan. Harga ikan dipasaran yang berasal dari sungai Sebangau antara $20.000-70.000 / \mathrm{kg}$, dan keberadaan ikan- ikan ini dapat ditemukan pada musimmusim tertentu.

Secara biologi ikan-ikan yang tertangkap di sungai Sebangau tergolong ikan-ikan pemangsa atau predator. Kondisi perairan gambut yang bercampur dengan sari pati tumbuhan dan dedaunan yang berwarna coklat dan dapat ditemukan daerah hutan rawa serta tingkat keasaman tanah gambut yang sangat tinggi dengan kadar $\mathrm{pH}$ antara 3 sampai 5. Sumber daya perikanan di sungai sebangau merupakan bagian integral yang tidak terpisahkan dari ekosistem rawa. Sumberdaya perikanan digolongkan sebagai suimberdaya yang dapat pulih (revewable resources) tetapi dibatasi oleh faktor pembatas alami dan faktor pembatas non alami (Haryuni et al 2019). 
Sungai Sebangu berada di sebelah timur barat dari taman nasional sebagau, dengan mempunyai panjang $\pm 198.515 \mathrm{~km}$ dan lebar $200 \mathrm{~m}$. Kondisi perairan gambut yang demikian menyebabkan sumberdaya ikan yang berasal dari tergolong dalam ikan jrnis-jenis ikan hitam (black fish) seperti famili Anabantidae. Menurut Utomo\& Samuel (2005) dalam Asyari (2006) jenis ikan yang biasa hidup pada ekosistem rawa banjiran (flood plain) yaitu kelompok ikan hitam.Hasil-hasil tangkapan ikan yang berasal dari sungai Sebangau ini dipasarkan di kota Palangka Raya juga dipasarkan ke Kabupaten dan Propinsi di luar Kalimantan Tengah, seperti ke Kalimantan Selatan. Di perairan umum hidup berbagai jenis ikan yang merupakan salah satu potensi sumberdaya perairan yang sangat potensial untuk dimanfaatkan terutama melalui penangkapan, namun penangkapan yang terus menerus berakibat menurunnya populasi ikan (Sweking et al 2011).

Tujuan dari penelitian ini adalah menganalisia aspek biologi ikan yang tertangkap di sungai Sebangau dan pemanfaatan bagi ekonomi nelayan yang menangkap ikan di sepanjang sungai Sebangau.

\section{METODE PENELITIAN}

Penelitian ini dilaksanakan pada bulan April sampai dengan Juni 2020. Sampel ikan berasal dari sungai Sebangau kota Palangka Raya, Kalimantan Tengah di daerah Perupuk Tunggal. Analisa ikan dilakukan di Laboratorium Fakultas Perikanan Universitas Kristen Palangka Raya. Aspek biologi ikan yang dianalisis adalah hubungan panjang dan berat ikan, pengukuran yang digunakan adalah panjang total yaitu mulai dari ujung mulut sampai ke sirip ekor ikan dengan menggunakan penggaris satuan centimeter; Kebiasaan makan ikan dengan menganalisis jenis-jenis makanan yang terdapat dalam lambung ikan yang selanjutnya diidentifikasi. Penentuan hubungan panjang berat dilakukan dengan menggunakan rumus (Effendi, 1979) :

$$
\begin{aligned}
& W=a L^{b} \\
& \log W=\log a+b \log L
\end{aligned}
$$

Keterangan : $\mathrm{W}=$ Berat ikan (gram)

$\mathrm{L}=$ Panjang total ikan $(\mathrm{cm})$

a dan $b$ adalah konstanta

dari persamaan tersebut

Analisis kebiasaan makanan ikan untuk mengetahui jenis makanan utama/terbesar (Index of preponderance) yang dikemukanan oleh Natarjan dan Jhingran dalam Effendi (1979) sebagai berikut :

$$
\mathrm{IP}=\frac{\text { VixOi }}{\Sigma v i x \mathrm{O} i} \times 100 \%
$$

Keterangan :

$\mathrm{Vi}=$ persentase volume satu macam makanan

Oi $\quad=$ persentase frekuensi kejadian satu macam makanan

VixOi = jumlah VixOi dari semua jenis makanan

IP = index of preponderance

Adapun untuk mengetahui manfaat ekonomi ikan bagi masyarakat/nelayan dilakukan dengan mengumpulkatan data kuantitatif menggunakan instrumen kuisioner atau lembar cheklis. Kuisionr yang diberikan kepada masyarakat/nelayan berupa angket yang berisikan beberapa pertanyaan tentang data demografis, seperti jenis kelamin, usia, jumlah keluarga, pekerjaan utama, penidikan terakhir, jenis ikan tertangkap, alat tangkap yang digunakan, jumlah hasil tangkap untuk 1 hari, jumlah penghasilan sebulan, dan rata-rata harga ikan $1 \mathrm{~kg}$. Data kualitatif berupa teknik pengamatan dan wawancara tidak terstruktur. Data dianlaisis secara deskriptif dengan menjelaskan dan menguraikan semua variabel yang diamati selama penelitian (Mahin, 2011). 


\section{HASIL DAN PEMBAHASAN}

\section{Aspek Biologis, Habitat dan Distribusi}

Aspek biologis yang dianalisa adalah panjang berat, kebiasaan makanan, dan Tingkat Kematangan gonad ikan dengan jumlah ikan yang dianalisis berjumlah 114 ikan. Jenis ikan yang dianalisa adalah ikan gabus, ikan Kehung, ikan Kerandang dan ikan Kapar, yang tertangkap dari sungai Sebangau, dapat dilihat pada Gambar 1.

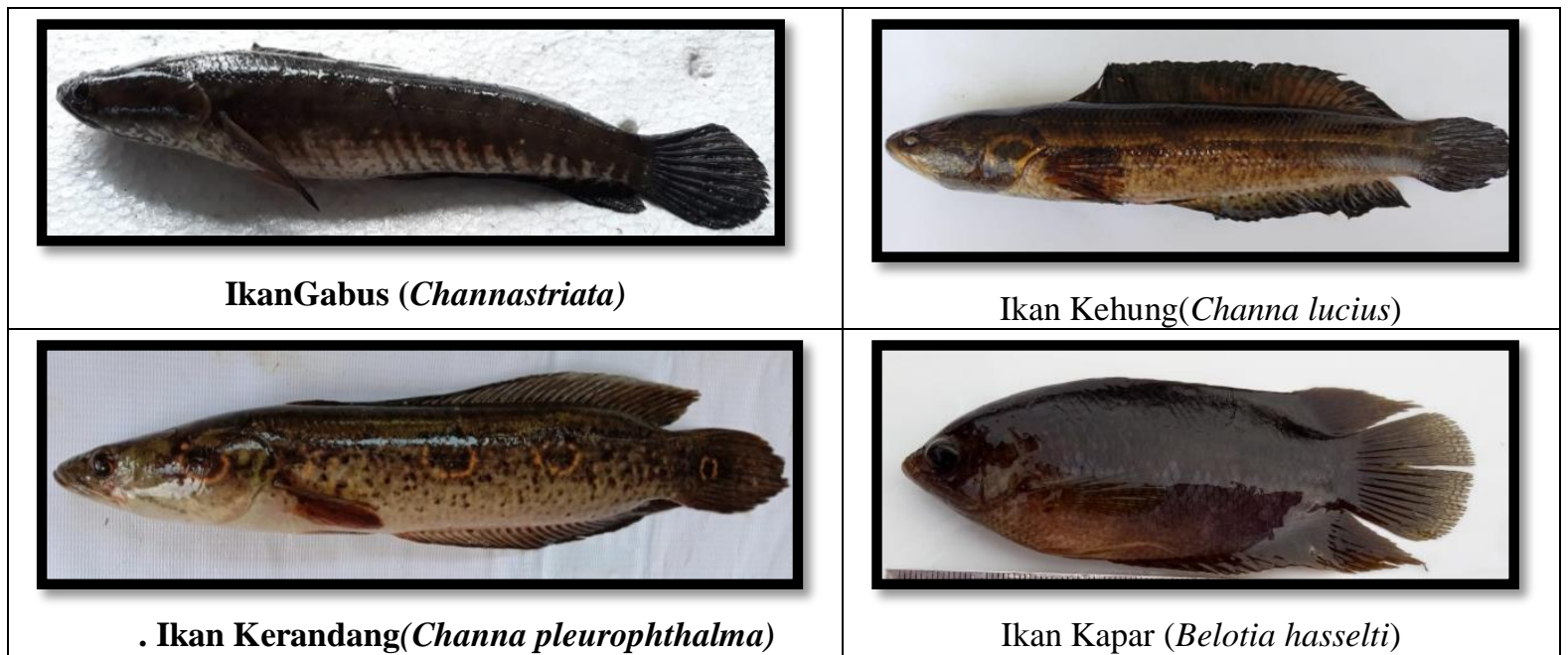

Gambar 1. Ikan Yang Tertangkap di Sungai Sebangau

Analisis regresi liner hubungan panjang dan berat ikan menunjukkan adanya keeratan hubungan antara panjang dan berat ikan. Nilai koefisien diterminasi $\mathrm{R}^{2}$ ikan kehung adalah sebesar 0,8804, ikan kapar 0,8914, ikan kerandang 0,9571 dan ikan Gabus 0,9011. Nilai $\mathrm{R}^{2}$ mendekati 1 menunjukkan pertambahan panjang ikan seiring dengan bertambah bobot tubuh ikan.

Tabel 1. Data Panjang dan Berat Ikan Yang Tertangkap Di Sungai Sebangau Kota Palangka Raya, Kalimantan Tengah

\begin{tabular}{llccc}
\hline No & Jenis Ikan & $\begin{array}{c}\text { Jumlah ikan } \\
\text { (ekor) }\end{array}$ & $\begin{array}{c}\text { Rata-rata } \\
\text { Panjang (cm) }\end{array}$ & $\begin{array}{c}\text { Rata-rata } \\
\text { Berat (gram) }\end{array}$ \\
\hline 1. & Kehung (Channa lucius) & 25 & 22,82 & 102,56 \\
2. & Kapar (Belontia hasselti) & 63 & 10,35 & 16,44 \\
3. & Kerandang(Channa pleurophthalma) & 13 & 31,5 & 294 \\
4 & Gabus (Channa striata) & 13 & 154 & 27,1 \\
\hline
\end{tabular}

Hasil penelitian menunjukkan bahwa pola pertumbuhan dari keempat jenis ikan yang diuji menunjukan bahwa secara umum bersifat allometrik positif, hal ini berarti bahwa pertambahan panjang ikan tidak secepat pertambahan berat. Pertumbuhan dapat dikatakan sebagai pertambahan ukuran panjang atau berat didalam waktu tertentu, pertambahan ukuran ini karena adanya proses hayati yang terus menerus terjadi didalam tubuh organisme (Arifin 1991). Ikan kerandang (Channa pleurophthalma) dapat mencapai ukuran lebih dari $50 \mathrm{~cm}$ (Kottelat et al., (1993).

Hasil analisis lambung ikan untuk mengetahui kebiasan makanan ikan yang tertangkap di sungai Sebangau diperoleh jenis makanan yang dominan dengan nilai IP untuk ikan Kehung 87\%, Gabus 99\% 
dan Kerandang $95 \%$ adalah anak ikan. Sedangkan untuk ikan kapar di dominasi makanan berupa tumbuhan IP 72\%. Dilihat dari kebiasaanmakan, ikan gabus dan ikan kerandangdan ikan kehung pemakan daging atau ikan karivora, sedangkan ikan kapar tergolong ikan omnivora.

Ikan kapar adalah golongan ikan omnivora, yaitu ikan pemakan tumbuhtumbuhan dan hewan. Makanan ikan kapar yaitu tanaman air, zooplankton dan serangga kecil. Ikan gabus biasa didapati di danau, rawa, sungai, dan saluran-saluran air hingga ke sawah-sawah. Ikan ini memangsa aneka ikan kecilkecil, serangga, dan berbagai hewan air lain termasuk berudu dan kodok. Menurut Nikolsky (1963), urutan kebiasaan makanan terdiri dari makanan utama (makanan yang biasa dimakan dalam jumlah banyak), makanan pelengkap (makanan yang ditemukan dalam saluran pencernaan dalam jumlah sedikit), makanan tambahan (makanan yang ditemukan dalam saluran pencernaan dalam jumlah sangat sedikit), makanan pengganti (makanan yang dikonsumsi jika makanan utama tidak tersedia).

Habitat dari ikan Gabus, ikan Kehung, ikan Kerandang dan ikan kapar di sungai Sebangau dicirikan dengan warna air hitam dengan dominasibanyak tumbuhan rasau dan tumbuhan bakung di kiri dan kanan sungai Sebangaun kondisi kualitas air dapat dilhat pada Gambar 2.

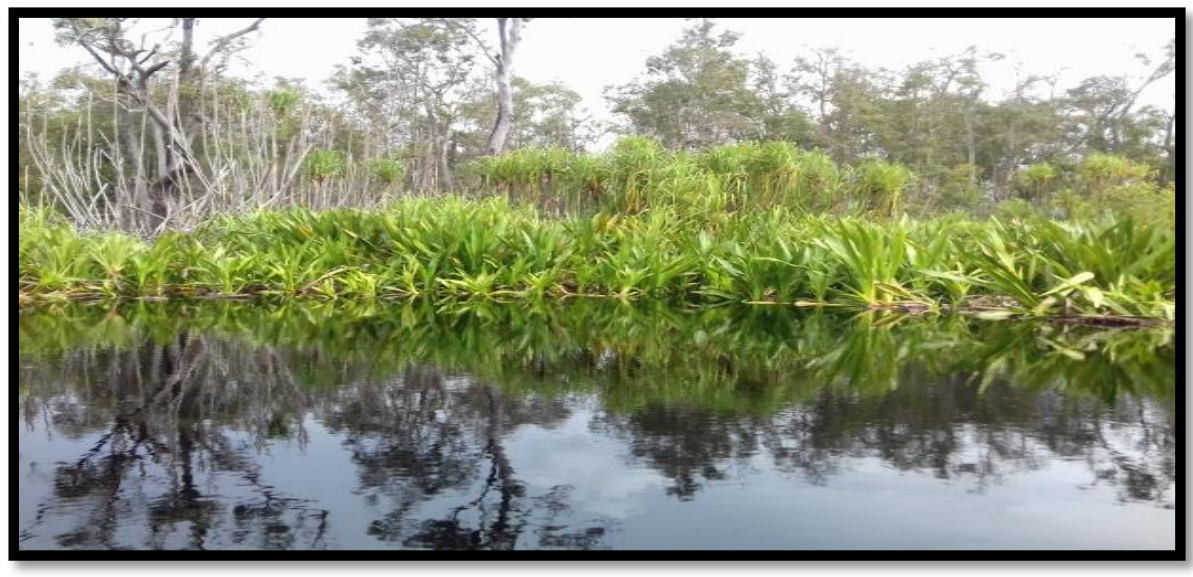

Gambar 2. Sungai Sebangau Kota Palangka Raya, Kalimantan Tengah

Sungai Sebangau merupakan kawasan hutan rawa gambut ciri khas mempunyai warna air hitam dan tumbuhan air yang di dominasi oleh tumbuhan air jenis rasau atau selingsing (Pandanus helicopus) dan tumbuhan bakung (Hanguana malayana) yang berada di sepanjang sungai Kualitas air sungai sebangau hasil penelitian untuk suhu berkisar antara $30,97^{\circ} \mathrm{C}-32,5^{\circ} \mathrm{C}$, DO 4,03-4,10 mg/l dan $\mathrm{pH} 3,56-4,24$, kedalaman air antara 1,3-6,5 m. Nilai $\mathrm{pH}$ yang rendah, menurut Pescod (1973) bahwa $\mathrm{pH}$ yang rendah masih cukup baik untuk kehidupan ikan dan organisme lainnya. Hidrologis kawasan sebangau merupakan daerah dengan kawasan yang relatif bervariasi karena pada saat musim hujan kawasan sepanjang sungai sebangau merupakan daerah rawa banjiran yang tergenang oleh air sedangkan pada musim kemarau kawasan ini mengalami kekeringan dan rawan terhadap bencana kebakaran hutan dan lahan.

Ikan gabus, kerandang dan ikan kehung adalah jenis ikan dapat hidup di sungai, danau, dan kolam serta biasa membuat sarang di daerah rawa-rawa atau diantara belukar yang terdapat pada tepi sungai. Sedangkan untuk ikan banyak di temukan pada perairan yang banyak ditumbuhi tumbuh-tumbuhan air. Menurut Selvina et al (2020) bahwa tempat pemijahan ikan gabus berada pada bagian 
hilir perairan rawa bajiran aliran sungai Sebangau.

Daerah penangkapan ikan (fishing ground) jenis ikan gabus, ikan kehung, ikan kerandang dan ikan kapar adalah di sepanjang DAS Sebangau berada pada anak sungai yang berhubungan langsung dengan sungai Sebangau dengan ekosistemnya merupakan ekosistem rawa banjiran, dimana di sepanjang sungai merupakan daerah rawa, dengan jenis tumbuhan tingkat rendah dan merupakan kawasan khusus penangkapan ikan.

Alat tangkap ikan yang digunakan oleh nelayan di sungai Sebangau adalah jenis tampirai, rawai (long line), banjur (Stake line), bubu (portable traps), pangilar, jala (cast net), rengge (gillnet). Alat tangkap yang digunakan lebih bersifat pasif berupa perangkap. Transportasi yang digunakan oleh nelayan untuk menangkap ikan adalah menggunakan perahu kecil kelotok/alkon/ces (bahasa daerah).

Hasil tangkap dijual kepada pengumpul ikan, dengan harga ikan bervariasi antara Rp. 20.000,- sampai dengan Rp. 60.000,-. Berdasarkan hasil wawancara dengan nelayan di Sungai Sebangau kota Palangka raya, bahwa penghasilan rata-rata 3-4 juta rupiah per bulan, sendangkan pada masa puncak ikan bulan September hingga bulan Desember, pendapatan bisa mencapai delapan juta per bulan.Potensi perikanan tangkap di DAS Sebangau cukup tinggi meskipun keragaman ikan yang ada di DAS ini tidak terlalu beragam. Meskipun pada waktuwaktu tertentu jumlah hasil tangkapan menurun, namun pada umumnya nelayan dapat terus menjalani aktifitas mencari ikan sepanjang tahun,bahkan pada saat tertentu hasil tangkapan bisa melimpah ruah. Menurut Mahin (2011) bahwa nelayan di sungai Sebangau kota Palangka Raya, menyukai situasi alam yang serba teratur (alam, cuaca dan iklim) sehingga hasil tangkapan dan pendapatan yang teratur. Ikan gabus Channa striata) termasuk ikan ekonomis selain ikan toman (Channa micropeltis) dan ikan Tapah
(Wallago leeri) yang berasal dari sungai Sebagau. Menurut Minarni et al (2012) beberapa jenis yang memiliki nilai ekonomis tinggi, misalnya Papuyu (Anabas Testudineus), toman (Channa micropeltis), gabus (Channa striata) dan sepat rawa (Trichogaster trichopterus), patin (Pangasius $S p$ ). Selain itu ikan gabus juga mengandung albumin yang baik untuk tubuh manusia (Mustafa et al 2012).

\section{KESIMPULAN}

Analisis hubungan panjang dan berat ikan menunjukkan adanya keeratan hubungan antara panjang dan berat ikan dengan pola pertumbuhan bersifat allometrik positif, berarti pertambahan panjang ikan tidak secepat pertambahan berat. Hasil kebiasaan makanan ikan diketahui untuk ikan Kehung, ikan Gabus dan ikan Kerandang tergolong ikan karnivora, dengan makanan utama anak ikan. Sedangkan untuk ikan kapar tergolong ikan omnivora dengan makanan utama tumbuhan. Secara ekonomi sumber daya ikan yang berasal dari sungai Sebangau terutama ikan Gabus (Channa striata), mempunyai nilai ekonomis penting baik untuk memenuhi kebutuhan gizi keluarga juga sebagai sumber pendapatan.

\section{DAFTAR PUSTAKA}

Asyari. 2006. Karakterisktik Habitat dan Jenis Pada Beberapa Suaka Perikanan Di Daerah Aliran Sungai Barito, Kalimantan Selatan. Jurnal Ilmu-ilmu Perairan Indonesia. 13(2), 155-163.

Arifin. 1991. Pertumbuhan Ikan. Penebar Swadaya. Jakarta.

Effendi, M.I. 1979. Metode Biologi Perikanan. Yayasan Dewi Sri. Bogor. 112 pp

Haryuni. Najamuddin. Subhan A. A, \&Firlianty. (2019). Stok Ikan 
Tapah (Wallago leeri) Yang Tertangak Dengan Menggunakan Alat Tangkap Pangilar (Pot Trap) Di Sungai Sebangau Kota Palangka Raya. Enviro Scienteae. 15(1), $33-42$.

Mahin M. 2011. Kehidupan Sosial Ekonomi Nelayan Di Sebangau Kalimantan Tengah. WWF Indonesia Kalimantan Tengah.

Minggawati, I. Lukas, \& Mantuh, Y. (2020). Bookchapters : Dampak Covid-19 Bagi Kesehatan, Pendidikan, Ekonomi ., Proses Domestikasi Ikan Lokal Yang Tertangkap Dari Sungai Sebangau Kota Palangka Raya. Ideas Publishing.

Minarni I.Chandrawidjaja \& Novitasari. 2012. Kajian Pengembangan Rawa (Studi Kasus Rawa Kalahien Kabupaten Barito Selatan). Jurnal Teknologi Berkelanjutan. 1(2), 95103.

Mustafa, A. Widodo M.A. \& Kristianto Y. 2012. Albumin And Zinc Content Of Snakehead Fish (Channa striata) Extract And Its Role In Health. International Journal of Science and Technology (IJSTE).1(2), 1-8.
Nikolsky, G. V. 1963. The Ecology of Fishes. Academic Press. 315 pp.

Pescod, M.B. 1973. Investigation of rational effluent and straum standars for tropical continues, AIT. Bangkok, 59 pp.

Selvina E. Affandi R. Mukhlis K.M. 2020. Aspek Reproduksi Ikan Gabus (Chana striata) di Rawa Bajiran Aliran Sungai Sebangau, Palangka Rya. Junal Ilmu Pertanian Indonesia (JIPI). 25(1), 10-18.

Sweking. Mahyudin, I. Mahareda, E.S \& Salawati, U. 3011. Produksi dan Jumlah Ikan Yang Tertangkap Oleh Nelayan Di Sungai Kahayan Kecamatan Pahandut Kota Palangka Raya Propinsi Kalimantan Tengah. Enviro Scienteae. 7(2011), 39-49.

Kottelat M, Whitten AJ, dengan Kartikasari SN, dan Wirjoatmodjo S. 1993. Ikan Air Tawar di Indonesia Barat dan Sulawesi. Periplus Edisi (HK), Jakarta 